\title{
The Impact and Value of a Tourism Product: A Hybrid Sustainability Model
}

\author{
José Pablo Abeal Vázquez ${ }^{1, * \mathbb{D}}$, Pilar Tirado-Valencia ${ }^{2}$ (D) and $^{-}$Mercedes Ruiz-Lozano ${ }^{2}$ (D) \\ 1 Department of Business, University of A Coruña, 15071 Campus de Elviña A Coruña, Spain \\ 2 Department of Finance and Accounting, Universidad Loyola Andalucía, 14004 Córdoba, Spain; \\ ptirado@uloyola.es (P.T.-V.); mruiz@uloyola.es (M.R.-L.) \\ * Correspondence: j.abeal@udc.es
}

check for updates

Citation: Abeal Vázquez, J.P.;

Tirado-Valencia, P.; Ruiz-Lozano, M. The Impact and Value of a Tourism Product: A Hybrid Sustainability Model. Sustainability 2021, 13, 2327. https://doi.org/10.3390/su13042327

Academic Editor:

José António C. Santos

Received: 30 November 2020

Accepted: 16 February 2021

Published: 21 February 2021

Publisher's Note: MDPI stays neutral with regard to jurisdictional claims in published maps and institutional affiliations.

Copyright: (c) 2021 by the authors. Licensee MDPI, Basel, Switzerland. This article is an open access article distributed under the terms and conditions of the Creative Commons Attribution (CC BY) license (https:// creativecommons.org/licenses/by/ $4.0 /)$.

\begin{abstract}
The concepts of social value creation and sustainability are acquiring a growing relevance in the vision shared by the tourism industry's major stakeholders. Our aim was to determine a hybrid impact-value model capable of measuring tourism product sustainability through the use of indicators and the impact of stakeholder actions during the process of creating and generating products. An initial static vision of sustainability is complemented by a second dynamic vision, based on the measurement of value and change. The proposed model includes the same stakeholders, dimensions and indicators for both approaches. This standardization enhances the robustness of the model and its potential as an analysis instrument. After reviewing the considerable number of possible impact measurement techniques, we opted for the versatile methodology known as Social Return on Investment (SROI).
\end{abstract}

Keywords: impact measurement; social value; sustainability; indicators; tourism product; SROI; hybrid model

\section{Introduction}

Tourism is a phenomenon that combines sociocultural, environmental and economic aspects more than practically any other activity. It is one of the world's foremost industries in terms of job creation and economic development; however, the crisis caused by COVID19 has led to a dramatic downturn in this sense [1]. To a large extent, the competitiveness of a tourism destination depends on its sustainability. However, achieving sustainability in tourism is no easy task, hindered in part by the fuzzy nature of this concept. The sharp growth of the tourism industry in recent years has been accompanied by a growing interest in the study of overtourism. Indeed, even the tourists themselves are becoming increasingly aware of the adverse impacts their behavior may have.

The tourism industry includes a large number of public and private companies and institutions that promote the creation of products for travel, accommodation and destination activities and amenities. Their competitiveness depends on multiple factors, but a crucial element is the destinations' capacity to attract tourists by offering appealing quality services, as well as guaranteeing the efficient and sustainable use of resources [2]. In turn, the concept of the tourism product has evolved rapidly, in line with the growth and expansion of the tourism industry [3].

Twenty-five years ago, Robson and Robson [4] highlighted the need to promote the "stakeholder economy" and analyzed the complexities of this approach from the perspective of tourism. Measuring success before such a large set of stakeholders is complex and requires analytical tools capable of assessing the degree to which expectations are met in an efficient and sustainable manner. In an increasingly complicated scenario, governance systems are more dependent than ever on the interests of a heterogeneous set of agents and the alignment and fluency of the relationships between them. 
Many of the most common terms used in research into sustainability in tourism, such as impact, product or social value, can be used in widely diverse contexts, and therefore these concepts can occasionally lead to a degree of confusion. In this sense, authors such as Madsen and Zhang [5] identified a number of approaches for estimating the regional and local impacts of tourism, and determined that the results vary considerably, in accordance with the approach adopted.

Following the publication of the Brundtland Report [6], there has been a sharp hike in the number of sustainable development initiatives. The World Tourism Organisation (WTO) [7] defined sustainable tourism as that which considers present and future economic, social and environmental impacts, taking into account the needs of visitors, the industry, the environment and the community. However, sustainability in the tourism industry is still evolving, despite its rapid rise as an area of research, leading to the emergence of several research traditions [8]. For instance, some authors consider it to be more a desire than a measurable goal [9]. Guaranteeing the sustainability of tourism requires a profound insight into the complexity of tourism systems and the specificity of tourism destinations, as well as an awareness of the changes this activity generates in its environment. The work of Timur and Getz [10] reminds us that sustainable tourism must be based on the dimensions of economic, ecological and sociocultural sustainability.

To date, much of the research conducted in this area has centered on social, economic or environment indicators, tending to overlook their integration and relationship. Since the 1990s, multiple models have been developed to measure the social impact of public and not-for-profit organizations [11-14]. Maas and Liket [15] drew up a list of no fewer than thirty quantitative methods for impact measurement. Organizations can use these methods to quantify intangible results in order to measure social impact, as well as assessing and monitoring the efficiency of the decisions they adopt. In turn, in the light of the absence of a standardized terminology for the measurement of social impact, Lingane and Olsen [16] proposed a series of definitions in order to clarify this issue.

Regarding the management of tourism businesses, executive directors must be fully aware of the impact their actions have on society and the environment in order to obtain a full understanding of their performance in terms of sustainability. Although progress, in this sense, has been made, thanks mainly to a series of international standards [17,18], much remains to be done in order to define a reference framework capable of quantifying the value of an organization's impact on society and the environment.

The methodology for measuring social impact known as the Social Return of Investment (SROI) was initially intended for not-for-profit organizations; however, its use has now extended to all types of organizations and businesses [19-21]. This method provides a suitable tool for the construction of a model that measures the social value and impacts on sustainability generated by the creation and development of a tourism product from the perspective of all the various stakeholders involved [22].

Our main objective was to create a model capable of assessing sustainability from the perspective of impact, as well as value. In this sense, the initial phase consists of constructing a framework based on sustainable aspects of the main elements that comprise a tourism product [23]. Our aim was to draw up a sustainability map of the principal dimensions and stakeholders. The second phase involved measuring the change and value of the impact resulting from the actions underlying the creation and development of a tourism product. In order to do so, we applied SROI methodology based on a holistic perspective. In short, the ultimate aim was to measure change, assess its consequences and monitor any possible deviation from a predetermined objective.

The article begins by considering the concept of product from a tourism-based approach. It then goes on to consider the notion of sustainability and its intended analysis from varying perspectives. An insight into SROI methodology, social value and impact measurement precedes the proposal for a hybrid sustainability model for a tourism product based on impact and value. It ends with a discussion of the principal implications and 
future lines of research for the practical development and application of the various parts included in the model.

\section{Background}

\subsection{The Tourism Product}

According to the World Tourism Organization (see Reference [24], p.14), a tourism destination is "a physical space with or without administrative and/or analytical boundaries in which a visitor can spend an overnight. It is the cluster (co-location) of products and services, and of activities and experiences along the tourism value chain and a basic unit of analysis of tourism. A destination incorporates various stakeholders and can network to form larger destinations. It is also intangible with its image and identity which may influence its market competitiveness". Likewise, the tourism product is defined as ([24], p. 18) "a combination of tangible and intangible elements, such as natural, cultural and man-made resources, attractions, facilities, services and activities around a specific centre of interest which represents the core of the destination marketing mix and creates an overall visitor experience including emotional aspects for the potential customers. A tourism product is priced and sold through distribution channels and it has a life-cycle". Two major conclusions can be drawn from these definitions: Firstly, the concept of destination encompasses the tourism products themselves; and secondly, the relationship between destination, product and the elements included in the tourism product, many of which are intangible, is a highly complex one.

The structure of the tourism product and the process underlying its creation hold considerable complexities. Santos et al. [25] proposed a framework for the design of innovative tourism products based on three elements: resources, stakeholder selection and the creation of transformative tourism experiences. Smith [23] broke down the tourism product into its basic elements: physical plant, service, hospitality, freedom of choice and involvement. The physical plant lies at the product core and is surrounded by four sequential layers that represent the remaining compositional elements. Freedom of choice, an element that varies significantly depending on the nature of travel, refers to visitors' need to have a wide range of options to choose from. In turn, involvement is more profound and intangible, linked to commitment and its association with the activity. A tourism product exists when all five elements are integrated in order to meet tourists' needs and expectations. Moving from the core to the outer elements implies reduced control and an increase in consumer participation, coupled with a greater degree of intangibility. In turn, this leads to a growing difficulty in the accurate measurement of the successive elements.

The success of a tourism product depends on the capacity of each element to integrate with the others. Therefore, generating a product requires the effective interaction of all five elements, not just their combination. The productive process begins with the physical plant, such as natural resources or infrastructures. During the following stages, service, hospitality, freedom of choice and tourist involvement are gradually integrated into the incipient product. Eventually, product and tourism process become indivisible. Identifying the stakeholder value variables is an essential aspect in the design and development of the tourism product and its elements $[10,26]$. This implies a shift from a tourism product model centered on tourist satisfaction to one focused on sustainability and the measurement of the generated impacts.

Taking Smith's model as a starting point, $\mathrm{Xu}$ [27] maintains the five elements described above, but confers varying degrees of importance in accordance with the diversity of tourism products. Physical plant remains the most important element. Indeed, Xu places physical plant at the centre of the model, surrounding it with the four remaining elements that play a supporting role, facilitating the production and consumption processes. The central physical plant determines satisfaction, associated with the minimum tangible needs. In contrast, the support elements generate satisfaction through experiences based on more sophisticated needs. Finally, it must be stated that all five elements vary in terms of their importance within the configuration of the tourism product. 
The tourism product is the starting point for our model and will also define its limits. The relationships between its various elements will be essential in defining the sustainability indicators of the various dimensions. In this sense, identifying the connections between the various elements of the tourism product under analysis is a prerequisite. Moreover, Santos et al. [25] stressed that the process for developing tourism products must be dynamic and cyclical, as it requires the ongoing assessment of the elements that characterize them.

Due to the diversity that characterizes tourism products, the literature has made major efforts to group them by typology. In this sense, McKercher [28] developed an integral approach with a proposal for a seven-level taxonomy for tourism products, with more than twenty product families and ninety classes, grouped in accordance with the five needs they satisfy, namely pleasure, personal quest, human endeavor, nature and business. In his study, this author successful identified the majority of tourism product offers, highlighting their wide diversity and the need for specific sustainability indicators for each product type. In other words, a core of common indicators and a specific set for each type.

\subsection{Stakeholders and Tourism}

The inclusion of stakeholders in the economic equation has ethical implications. Over the last few years, many authors have addressed the stakeholder issue [29-31], including from the perspective of a systematic review of the Stakeholder Theory [32]. The first of these was Freeman [33], who claimed that companies were obliged to protect all those stakeholders with an interest and involvement in these businesses' goals, not just their shareholders.

According to Goeldner and Ritchie [34], key stakeholders include tourists, residents, business owners and local public workers. The disparity of their often conflicting interests complicates and may even prevent the possibility of consensus-based solutions for the group as a whole [35]. The impact of tourism has been studied from various perspectives. Byrd et al. [36] analyzed differences in the perceptions of the impact of tourism in rural areas of the United States among four stakeholder groups (residents, business owners, public workers and tourists). Kuvan and Akan [37] studied two stakeholder groups (local residents and tourist facility managers), whilst Poudel et al. [38] studied two protected areas of Nepal, comparing residents and tourists' responses. In turn, González Herrera et al. [39] assessed tourism development from the perspective of visitors and residents. Essentially, these studies point to a degree of flexibility in the use of the stakeholder concept, focusing on identifying priority stakeholders for the various types of tourism products, as well as analyzing the material issues of greatest concern, either due to their impact or social value.

As for the relevance of the question of governance, a number of authors have hailed it as an essential requirement for achieving sustainability in tourism [40]. However, it also entails a series of major difficulties, the result of both the multiple interests involved and the difficulty of ensuring the necessary consensus among the various stakeholders [41]. In this sense, the various governance strata have shown a growing interest in and commitment to contemporary tourism development. Ruhanen [42] identified this reality for local government, but it is not exempt from problems that have complicated its sustainable development.

Numerous studies have addressed the dimensions of sustainability and its relationship with stakeholders. Sautter and Leisen [43] concluded that collaboration is essential in securing sustainable development. In the case of cruise destinations, the study by James et al. [44] determined that there is a need for agreements and collaboration between stakeholders. Likewise, Vellecco and Mancino [45], in a case study located in Italy, showed that conflict within the local community is detrimental to environmental conservation based on innovative approaches. Niñerola et al. [46] observed a significant growth in the literature addressing sustainability in tourism, which is emerging as a strategic aspect for tourism businesses and destinations; however, putting these strategies into practice is still in its early days. The local population of a tourism destination is crucial for the industry. Scholtz and Slabbert [47] found that the intangible social impacts of tourism play a vital role in fomenting community support. In turn, and in relation to natural disasters, 
Chan et al. [48] studied the 2018 Hokkaido Eastern Iburi earthquake in Japan, determining that collaboration was the key factor in the resilience shown by this destination.

In the light of the current context, tourism must commit to the trend for sustainable development. Sustainability is a dynamic process, yet it is unclear how this concept should be integrated into the various levels of planning by both private enterprise and public administrations. When assessing the progress that has been made towards achieving sustainable tourism, stakeholders' perceptions must be taken into account in order to identify the extent to which tourism satisfies the interests of residents and tourists, whilst at the same time protecting the environment and other social and cultural elements. As a result, measuring the performance of organizations operating within the sector will provide a more integral vision, as it includes the expectations of a broader group of stakeholders.

\subsection{Sustainability and Tourism}

The need to research performance in sustainability has become a critical issue for the sector [49-51]. Efforts must be channeled into defining a series of personalized performance indicators that (1) support the decision-making process, (2) assess performance in order to prevent unsustainable actions, (3) are capable of measuring the impacts generated and (4) inform society as a whole of the results achieved.

Moyle et al. [52] conducted a study into sustainability that consisted of analyzing the strategic plans for tourism in Australia on a national, state, regional and local level. They observed a slight rise in the use of the concept of sustainability over the last decade. Similarly, they detected a change in the conceptualization of sustainability, consisting of the shift of nature or social based concepts towards a perspective centered more on climate change or responsibility.

Today, there is a generalized consensus that tourism planning should be based on multi-dimensional sustainability goals [53]. This requires instruments that provide an insight into the situation of the various destinations and tourism products, whilst at the same time creating public sector measures that will improve sustainability [54]. In order to achieve sustainable development, all of those organizations involved in tourism destinations must simultaneously achieve a broad set of objectives. A further requirement is the introduction of a system that guarantees sustainable practices and takes into account the complexities of stakeholders' expectations and the networks they forge and develop. In the case of Finland, Renfords [55] determined that economic sustainability is the most important dimension, whilst sociocultural sustainability is the weakest and most complex.

In this sense, Ko [56] considers that a model for assessing sustainable development in tourism should provide a systemic manner of organizing, combining and measuring indicators centered on stakeholders' expectations and impact evaluation. This model may take the form of multiple combinations. Ko [57] developed a practical approach for assessing tourism sustainability based on a set of stages. The process begins by identifying the systems, dimensions and indicators. It then proposes scaling the indicators and determining the degrees of sustainability, before developing sustainability assessment maps in order to analyze the results over various periods. In turn, Franzoni [58] proposes a framework for identifying variables grouped on three levels (community, the tourism destination and individual organizations) and in various dimensions (social, competition and economic). Consequently, sustainable development would involve the balanced grouping of all of these dimensions.

\subsection{Sustainability and Impact Indicators}

Sustainability indicators form a large set characterized by varied segmentation [59]. Blancas et al. [60] proposed an indicator system to analyze the sustainability of tourism activity in rural destinations. The aim was to provide information that would allow for a deeper insight into the transition towards sustainability in specific destinations and to provide the managers of these destinations with the necessary tools. LozanoOyola et al. [61] adopted a practical approach, designed for use by local agents in order to 
boost destination sustainability, developing a system of compound indicators that would be simple to apply, measure and interpret. Ariza et al. [22] concluded that analyzing tourism activity indicators could contribute to providing stakeholder solutions for addressing the positive and negative social impacts of tourism.

Other authors, such as Asmelash and Kumar [62], came up with the idea of developing an integral set of indicators that would allow for the precise assessment of the move towards sustainable tourism. The dimensions of sustainability from this perspective are sociocultural, institutional, environmental and economic. There is a certain degree of overlapping, a point which requires close consideration when selecting the indicators for inclusion in our model.

Indicator choice and assessment must be adapted to the circumstances of each study. Liu et al. [63] focused on identifying sustainability indicators for festivals based on their stakeholders, namely tourists, residents, business owners and government agencies. Schianetz and Kavanagh [51] proposed a method for selecting and assessing sustainability indicators that included the relationship between sociocultural, economic and environmental aspects, duly reflecting the complex nature of tourism. In turn, Cucculelli and Goffi [64] used a set of sustainability indicators for a number of small destinations of excellence in Italy, establishing a positive relationship between sustainability factors and competitiveness indicators, which had a greater impact than other variables.

Together, these studies indicate that, when analyzing the competitiveness and sustainability of tourism products, the indicators defined for management decision-making, even in the case of public administrations, which provide the funding for much of the sector's activity, are only rarely based on measuring the social impact on stakeholders [65].

\subsection{Social Value and Measuring Impact}

The field of economics has long used cost-benefit models to measure the economic impact of social programs. Cost benefit analysis can be applied at both the start and end of an investment in order to determine whether the forecasted targets have been met. Among the many authors that have addressed this issue, Olsen and Galimidi [66] compiled a series of approaches for impact measurement and offered a series of recommendations. Following Rosenzweig [67], Maas [68] based the approach used on the impact value chain, in order to differentiate between product results and impact. This latter approach proved particularly useful for the creation of our model. Maas [68] ordered the various methods in accordance with the following outline: purposes (screening, monitor, reporting and evaluation), time frame (prospective, ongoing and retrospective), orientation (input and output), length of time frame (short- and long-term), perspective (individual, company and society) and approach (process and impact methods, and monetarization).

The SROI method is a practical management tool that facilitates informed decisionmaking. It was developed from 1996 onwards by the Roberts Enterprise Development Fund [69]. Although this institution has not published any further reports since the turn of the 21st century, other institutions, such as the Social Value UK (formerly The SROI Network) have continued to actively redefine SROI methodology. Maas [68] considers that this approach combines the cost-volume-profit analysis and the financial analysis tools used in the private sector, although it focuses on what could be considered a social benefit. One of its particular strengths is its accessibility to a greater number of users.

As Lingane and Olsen [16] highlight, this analysis is of use to managers and investors in planning, administration and evaluation actions. Those involved in tourism management rarely include social cost-benefit analyses in their decision-making processes; however, they may occasionally be used to determine the most cost-efficient way of producing benefits or reducing the negative impacts of their activity on key stakeholders. In turn, this method enables senior managers to maximize the social and financial benefits. As for the users, they form a highly diverse group ranging from not-for-profit organizations and social enterprises to private businesses, fund providers and policy-makers. 
In operational terms, SROI Network [70] defines SROI as a framework for measuring and accounting for the concept of value. This method provides an insight into how change occurs and is accounted for by measuring the social, environmental and economic impacts. SROI analysis can be grouped into two major categories: evaluative and prospective. This latter approach is suitable for planning activities. Defining and constructing outcomes is crucial in order to guarantee quality data and reliable results. The SROI Network [70] upholds that it is preferable to predict social value, rather than merely evaluating past results.

SROI encompasses a broad concept of value. Furthermore, it is capable of monetizing intangible social value and expressing it in quantitative and comparable terms. The end product of this value monetization method should not be reduced to merely economic considerations. Indeed, SROI sheds light on the changes that have taken place during the process analyzed, as well as on stakeholders' perceptions. The process, the desired change and the plans in place to achieve it are all fundamental in understanding this approach. The idea is to combine activities and impact. The benefits are based on an integrated approach and improved contextualization. The Theory of Change, as a structured and systematic thought process [71], is of an eminently practical nature, and evolved from informed social practice and program assessment [72].

The flexibility of SROI also makes it highly adaptable, and it can therefore be widely applied to the social value generated by a company, or focused more specifically on a particular project or product. A further aspect makes it especially suitable for use in our approach in that it can be used either by the organization itself, or from the perspective of the project funders. As for the method's practical application for public administrations, Ruiz-Lozano et al. [65] analyzed its utility in the assessment of subsidy applications based on social criteria. However, despite its unquestioned utility for the sector, to date, very few studies have considered the application of SROI in tourism [22].

\section{A Hybrid Sustainability Model for Measuring Value and Impact}

Our model integrates two approaches. The first is inspired by Ko [57] and determines the Product Sustainability Assessment Map (PSAM) (Figure 1) and the Barometer for Tourism Product Sustainability (BTPS) (Figure 2) for each stakeholder. Together, they define the Global Sustainability Product Model (GSPM). The next stage is to identify or design the Product Sustainability and Impact Indicators (PSII) (Figure 3). These indicators are crucial in order to combine the two main parts of the model (GSPM and TPIM) for the various dimensions of each stakeholder.

The second approach, known as the Tourism Product Impact Model (TPIM) (Figure 4) is based on SROI methodology (from References $[70,73]$ ) and measures the impact of a specific action (e.g., an investment projects) on the tourism product subject to the analysis. The combination of these two models would lead to the Tourism Product Impact and Sustainability Model (TPISM) (Figure 5); in other words, the global version. It must be stressed that both parts of this global model can be applied separately; however, their combined use is far more beneficial in terms of the information provided.

Both models have a number of elements in common and use complementary analyses in order to reach a final shared objective. The first part of the model is static, and the second is dynamic, but both feed into a long-term vision. Our approach is based on the tourism product, sustainability, impact measurement and accounting for social value. Our model includes five stakeholders (enterprise, residents, public and private institutions, policy-makers and tourists) and four major dimensions for the sustainability indicators (sociocultural, economic, environmental and institutional). The stakeholders and sustainability dimensions defined are based on the approach most commonly described in the literature. However, we have also included the separate figure of the policy-maker, in order to establish a difference between political and institutional interests. The following section analyzes the two parts of the model separately. 


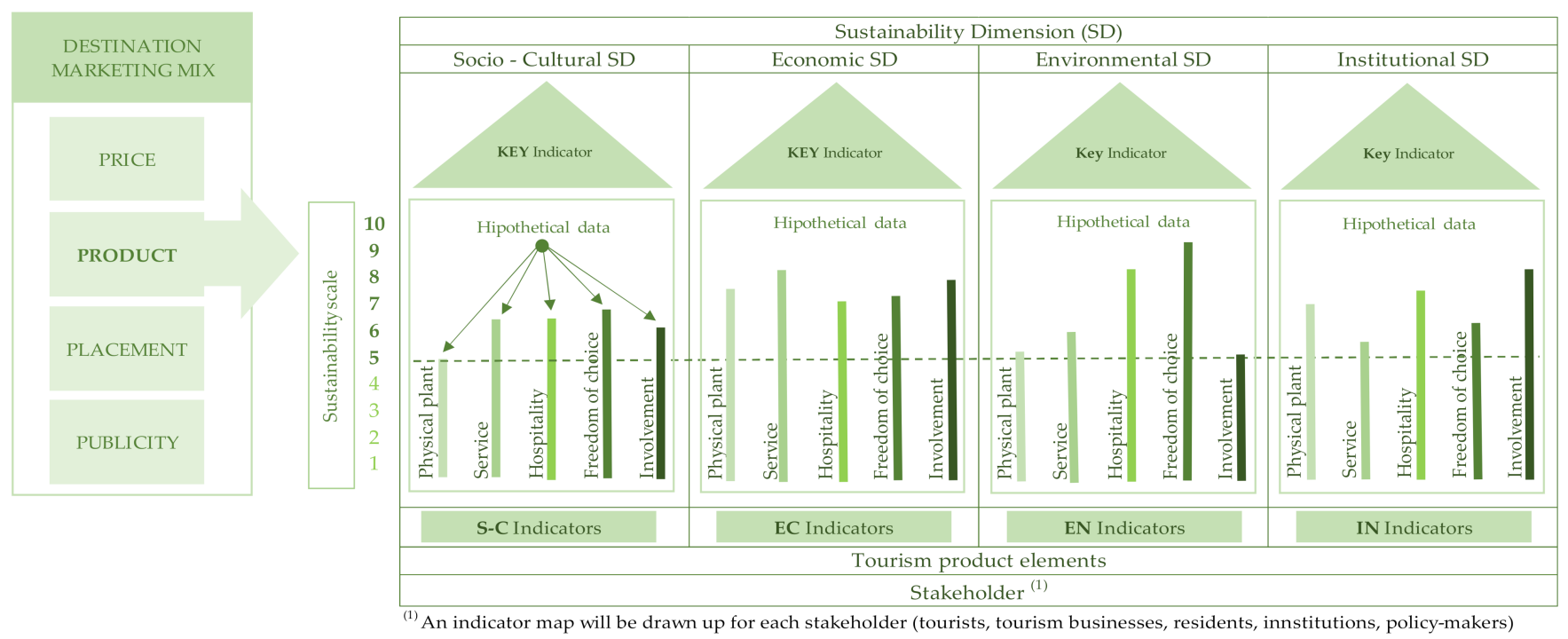

Figure 1. Product Sustainability Assessment Map (PSAM). Source: authors' own work.

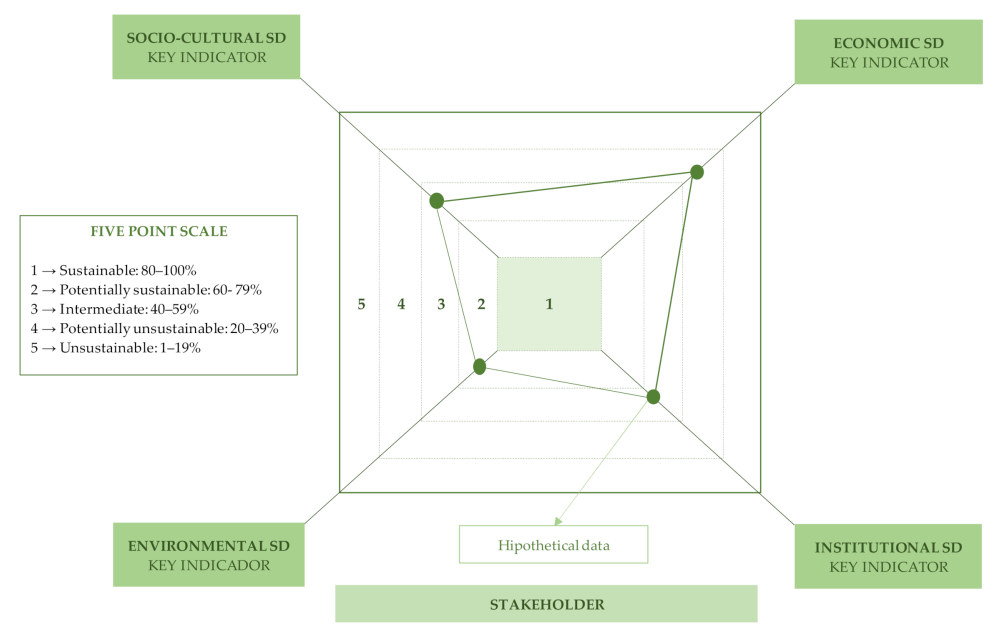

Figure 2. Barometer for Tourism Product Sustainability (BTPS). Source: authors' own work.

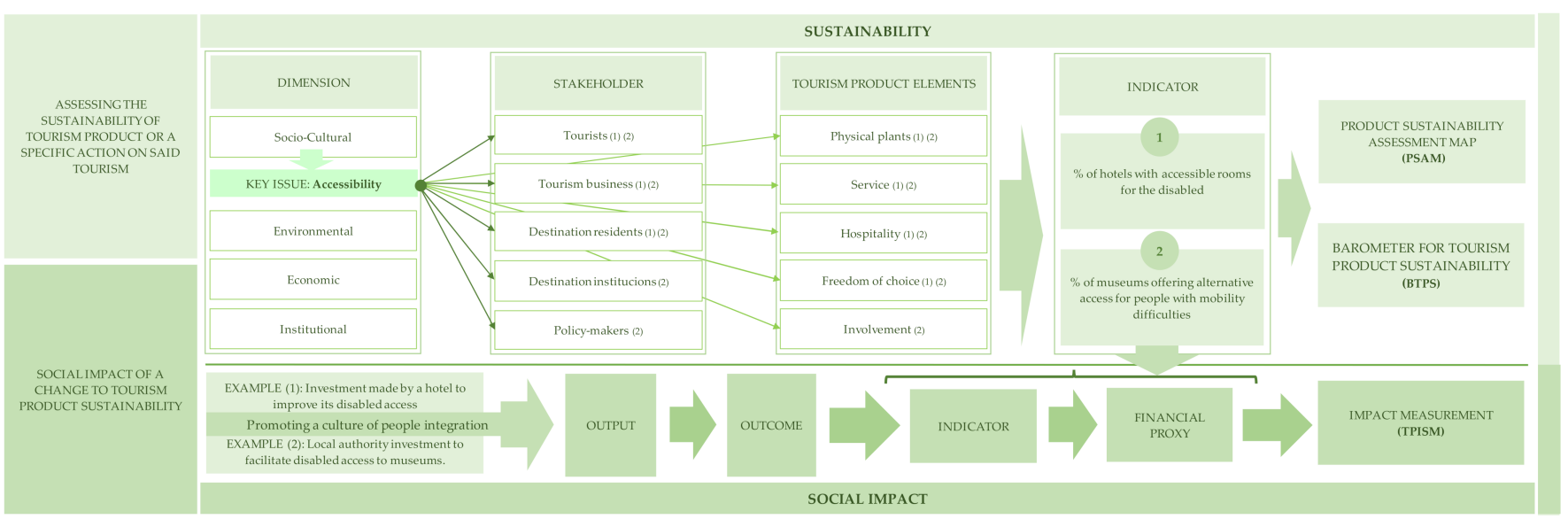

Figure 3. Product Sustainability and Impact Indicators (PSII) centered on the proposed example. Source: authors' own work. 


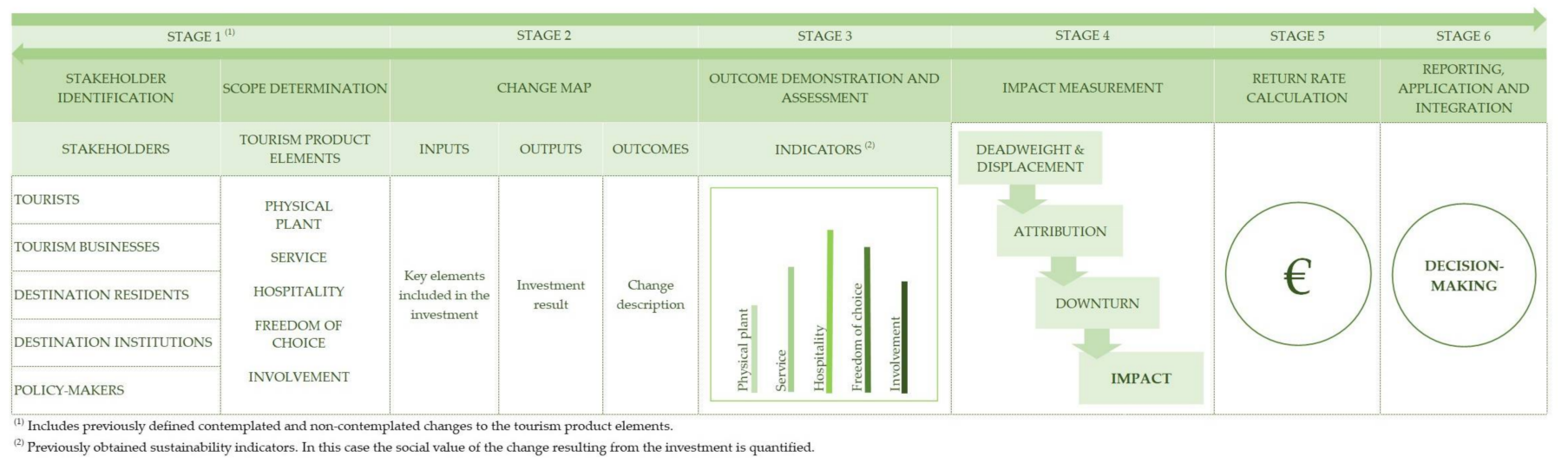

Figure 4. Tourism Product Impact Model (TPIM). Source: authors' own work, based on Reference [70].

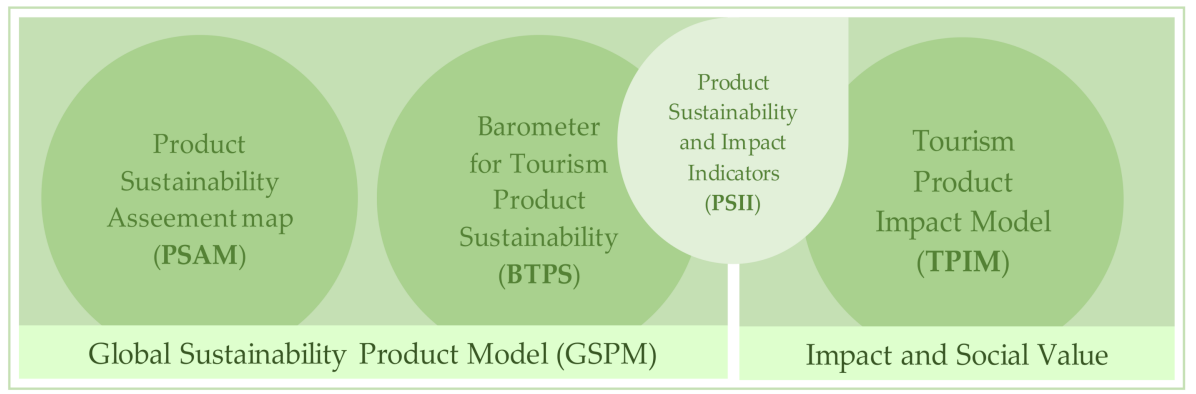

Figure 5. Tourism Product Impact and Sustainability Model (TPISM).

\subsection{Part One of the Model: The Sustainability of a Tourism Product}

Figures 1 and 2 show the resulting model for measuring tourism product sustainability. Taking the methodological outline proposed by Ko [57] as our starting point, we adapted it in accordance with our approach and tailored it to the nature of tourism products. Following Smith [23], the initial stage consists of identifying the principal elements of the tourism product. The product provides the reference framework for determining the dimensions of sustainability. These various dimensions are then identified as sociocultural, economic, environmental and institutional considerations. A disaggregated analysis is conducted for each stakeholder, distinguishing between the various elements of the tourism product.

The indicators of the specific dimension for each stakeholder are later summarized in a key indicator that includes the overall effect, which in turn is used in the BTPS for each stakeholder (Figure 2).

Sustainability scale and intensity must then be determined. In our case, and following Ko [57], we propose a complex five-point scale. This increases the difficulty and cost of obtaining data, but also allows for a more precise analysis. From here on, we are in a position to construct the PSAM (Figure 1) and the BTPS (Figure 2). Finally, the maps and barometers must be analyzed over several periods, in order to evaluate the sustainability of both the individual components and the tourism product as a whole.

\subsection{Product Sustainability and Impact Indicators}

The WTO [59] stresses that the choice of sustainability indicators must be duly justified: The data sources for calculating sustainability must be assessed in order to guarantee validity as an instrument for comparison and decision-making.

Figure 3 outlines the role indicators play in our representation. In order to provide a simplified representation of this process, we have included the Key Issue "Accessibility" as an example within the sociocultural dimension. Accessibility affects the elements that make up the tourism product; however, their intensity and the number affected may vary. In our case, we proposed two sustainability indicators: (1) the percentage of hotels with accessible 
rooms for the disabled and (2) the percentage of museums that offer alternative access for people with mobility difficulties. Applying this indicator requires the prior definition of the data sources (e.g., public statistics or specific stakeholder-targeted surveys).

These indicators address two complementary perspectives of destination management-business and political; however, both lead to a more intangible approach based on the integration of persons. The impact on the physical plant of the tourism product is clear. However, more intangible aspects, such as freedom of choice, may be less evident, even though their justification stems from the fact that improvements to these indicators increase our possibilities for applying our freedom of choice. These two indicators would converge with the other indicators designed for inclusion in the Barometer for Tourism Product Sustainability (BTPS).

After defining these two indicators, we considered two options for the social impact. Example (1): investment by a hotel in improving access for the disabled. Example (2): local authority investment in improving disabled access to museums. The outcomes are the two sustainability indicators described above. In order to determine the change, we would have to define an indicator that included freedom of choice and its impact on the change produced by the "number of people that appreciate the improved accessibility", with the proxy "the additional amount they would be willing to pay for enhanced accessibility".

\subsection{Part Two of the Model: Measuring Tourism Product Value and Change}

After completing the first part, we turned our attention to accounting for the change that a specific action, generally with financial backing, entails for a tourism product; in this case, the analytical resource used in the impact value chain. This model is based on the Theory of Change [71,72], as well as on SROI methodology [70,73] and its basic principles.

The elements included in the Theory of Change value chain (inputs, activities, outputs and outcomes) are used to measure the value generated by an action on the tourism product and its management from the perspective of both short- and long-term sustainability.

Feedback for the results obtained are looped back into the first part of the model, which was described in the previous section. However, this does not mean that they must necessarily be integrated; however, it is recommendable for the information provided to stakeholders.

The number of sustainability evaluation indicators, as defined in the previous phase, depends on the individual complexity of each of the elements included in the product and the relationships between them. The literature referred to in the previous sections provides a broad set of sustainability indicators that could be included for empirical contrasting purposes. Our chosen indicator system allows for the evaluation of sustainability from four perspectives (sociocultural, economic, environmental and institutional), as well as providing both a human and material vision.

The characteristics of the tourism product act as an element of change for the relationships between the various stakeholders. The detailed development at this stage of the model produces a list of the impacts generated for each stakeholder, taking into consideration the various dimensions of sustainability. Following their identification and quantification, the impacts provide a tool for decision-making and the efficient allocation of resources. In order to achieve this, the stakeholders must play an active role throughout the process, and their collaboration must be on a par with that of the first stage of the model.

In line with the standard approach to SROI methodology, we defined six development stages (Figure 4): (1) stakeholder definition (already completed) and determination of the scope in relation to the elements of the tourism product; (2) creation of the change map; (3) demonstration of the outcomes and their evaluation based on the indicators (obtained in the previous stage); (4) impact determination; (5) return calculation; and (6) reporting, use and integration for decision-making purposes. An initial question of vital importance is to align all the agents involved towards the target impact and define the members of the group that will be most affected. 
The results obtained in the second part are integrated into and complement those of the first part of the model. This provides us with a global and static vision of the tourism product, based on the results of the first part, as well as the dynamic and narrower vision obtained from the second level of analysis. Moreover, the process provides feedback that favors the control and application of changes that will allow for overall improvements to the product. In this sense, the analysis considers the absolute position of the product and its chronological evolutions, as well as allowing distinctions to be drawn regarding the intensity of the various actions over time, based on the overall evolution.

\subsection{The Full Model: Tourism Product Impact and Sustainability Model (TPISM)}

Figure 5 provides an overview of the model. It is divided into two parts: the sustainability and social value of the impacts generated. Although both parts were included in the creation of the model, they may also be used separately. The set of stakeholders are the recipients of the results. Nevertheless, the dimensions involved make it reasonable to assume that the creation of the model should fall mainly to an institution that deals with all the stakeholders (such as sector associations or tourism management organizations). The PSIs are the connection between both approaches and one of the key elements in the TPISM.

\section{Discussion and Conclusions}

\subsection{Findings and Implications}

This is the first proposal for a hybrid value-impact methodology applied to tourism products. Indeed, it is the first step in drawing up a scalable standard. However, it also holds immense potential as a tool for informed decision-making. The first part of the model assesses sustainability in global terms, whilst the second addresses the specific actions carried out in order to meet stakeholders' expectations. By using the same dimensions, indicators and stakeholders, the model allows for the analysis of the tourism product overall, as well as the impact of the most representative specific actions, evaluating their degree of sustainability in comparative terms over time, and in accordance with a series of previously established reference standards. The possibility of both short and long term positioning also contributes major added value.

The result is a global vision. This is of particular relevance for tourism policy-makers and businesses operating in the sector, as it enables them to assess the impact of both their strategic and operational decisions. In turn, it also provides residents with an efficient tool for controlling the effects of the proposed and/or executed projects. They are better informed, and political action can be observed with a greater degree of transparency.

The model we propose here can be used for planning a tourism product and conducting a dynamic evaluation with feedback based on the actual information generated, which may be of relevance to the managers responsible for decision-making. Furthermore, it allows for the analysis of both the global evolution and the impact of a specific project, thereby contributing to the selection and design of the most suitable actions for improving the tourism product from the perspective of all the stakeholders included in the value chain.

Lastly, the sustainability indicators system resulting from the application of the model would underpin the capacity for quantifying both the partial goals for each area of sustainability, as well as the overall objectives related to the final impact. The indicators can be used for monitoring the tourism planning phases from the various administrative levels, and the redesign of those policies that have failed to meet the proposed objectives. Indicator homogeneity allows for the analysis of the efficiency of the actions applied and their comparability, as well as that of the system as a whole.

\subsection{Future Research Directions and Limitations}

The efficiency of the model must be proven empirically, and adjustments need to be made to those aspects that were not assessed in the preliminary theoretical development. However, prior to embarking on this process, it is necessary to specify a number of elements included in our proposal. 
Firstly, the sustainability indicators to be used for each product element, dimension and stakeholder must be determined. The choice, creation and definition of the key indicators is another question of considerable significance, due to the complexities involved. A large number of sources must be consulted in order to collect all the necessary information, which must include both quantitative and qualitative data from primary and secondary sources. The intangible nature of several of the elements included in the tourism product and the underlying difficulty in using a rigorous evaluation system further add to the existing complexities.

Equally worthy of mention are the high costs involved in obtaining the data and maintaining the flow of information over time. Furthermore, the number of tourism products is considerable, and therefore standardization is a key objective in order to compare and assess various products and their management. The global standardization goal could be relegated in favor of an alternative goal based on product categories. In our opinion, urban tourism would be a suitable initial candidate for putting this model into practice.

Author Contributions: Conceptualization, J.P.A.V., P.T.-V. and M.R.-L.; methodology, J.P.A.V., P.T.-V. and M.R.-L.; validation, J.P.A.V., P.T.-V. and M.R.-L.; formal analysis, J.P.A.V., P.T.-V. and M.R.-L.; investigation, J.P.A.V., P.T.-V. and M.R.-L.; resources, J.P.A.V., P.T.-V. and M.R.-L.; writing-original draft preparation, J.P.A.V.; writing-review and editing, J.P.A.V., P.T.-V. and M.R.-L.; visualization, J.P.A.V., P.T.-V. and M.R.-L.; supervision, J.P.A.V., P.T.-V. and M.R.-L. All authors have read and agreed to the published version of the manuscript.

Funding: This research received no external funding.

Institutional Review Board Statement: Not applicable.

Informed Consent Statement: Not applicable.

Data Availability Statement: Not applicable.

Conflicts of Interest: The authors declare no conflict of interest.

\section{References}

1. World Tourism Organization. Covid-19 and Tourism; World Tourism Organization: Madrid, Spain, 2020.

2. Hunter, C. Sustainable tourism as an adaptive paradigm. Ann. Tour. Reseach 1997, 24, 850-867. [CrossRef]

3. Benur, A.M.; Bramwell, B. Tourism product development and product diversification in destinations. Tour. Manag. 2015, 50, 213-224. [CrossRef]

4. Robson, J.; Robson, I. From shareholders to stakeholders: Critical issues for tourism marketers. Tour. Manag. 1996, 17, 533-540. [CrossRef]

5. Madsen, B.; Zhang, J. Towards a new framework for accounting and modelling the regional and local impacts of tourism. Econ. Syst. Res. 2010, 22, 313-340. [CrossRef]

6. World Commission on Environment and Development. Our Common Future: Report of the World Commission on Environment and Development; Oxford University Press: Oxford, UK, 1987.

7. WTO (UNEP). Making Tourism More Sustainable A Guide for Policy Makers; WTO: Madrid, Spain, 2005.

8. Saarinen, J. Critical sustainability: Setting the limits to growth and responsibility in tourism. Sustainability 2014, 6, 1-17. [CrossRef]

9. Moscardo, G.; Murphy, L. There is no such thing as sustainable tourism: Re-conceptualizing tourism as a tool for sustainability. Sustainability 2014, 6, 2538-2561. [CrossRef]

10. Timur, S.; Getz, D. Sustainable tourism development: How do destination stakeholders perceive sustainable urban tourism? Sustain. Dev. 2009, 17, 220-232. [CrossRef]

11. Ebrahim, A.S.; Rangan, V.K. The Limits of Nonprofit Impact: A Contingency Framework for Measuring Social Performance-HBS Working Knowledge; Harvard Business School: Boston, MA, USA, 2010; No. 10-099.

12. Arvidson, M.; Lyon, F. Social Impact Measurement and Non-profit Organisations: Compliance, Resistance, and Promotion. Voluntas 2014, 25, 869-886. [CrossRef]

13. Grieco, C.; Michelini, L.; Iasevoli, G. Measuring Value Creation in Social Enterprises: A Cluster Analysis of Social Impact Assessment Models. Nonprofit Volunt. Sect. Q. 2015, 44, 1173-1193. [CrossRef]

14. Gibbon, J.; Dey, C. Developments in social impact measurement in the third sector: Scaling up or dumbing down? Soc. Environ. Account. J. 2011, 31, 63-72. [CrossRef]

15. Maas, K.; Liket, K. Social Impact Measurement: Classification of Methods. In Environmental Management Accounting and Supply Chain Management; Springer: Dordrecht, The Netherlands, 2011; pp. 171-202.

16. Lingane, A.; Olsen, S. Guidelines for Social Return on Investment. Calif. Manage. Rev. 2004, 46, 116-135. [CrossRef] 
17. Medrado, L.; Jackson, L.A. Corporate nonfinancial disclosures: An illuminating look at the corporate social responsibility and sustainability reporting practices of hospitality and tourism firms. Tour. Hosp. Res. 2016, 16, 116-132. [CrossRef]

18. Hahn, R.; Kühnen, M. Determinants of sustainability reporting: A review of results, trends, theory, and opportunities in an expanding field of research. J. Clean. Prod. 2013, 59, 5-21. [CrossRef]

19. Maier, F.; Schober, C.; Simsa, R.; Millner, R. SROI as a Method for Evaluation Research: Understanding Merits and Limitations. Voluntas 2015, 26, 1805-1830. [CrossRef]

20. Gargani, J. The leap from ROI to SROI: Farther than expected? Eval. Program Plann. 2017, 64, 116-126. [CrossRef] [PubMed]

21. Nicholls, J. Social return on investment-Development and convergence. Eval. Program Plann. 2017, 64, 127-135. [CrossRef] [PubMed]

22. Ariza-Montes, A.; Sianes, A.; Fernández-Rodríguez, V.; López-Martín, C.; Ruíz-Lozano, M.; Tirado-Valencia, P. Social Return on Investment (SROI) to Assess the Impacts of Tourism: A Case Study. SAGE Open 2021, 11. [CrossRef]

23. Smith, S.L.J. The tourism product. Ann. Tour. Res. 1994, 21, 582-595. [CrossRef]

24. World Tourism Organization [UNWTO]. UNWTO Tourism Definitions; World Tourism Organization [UNWTO]: Madrid, Spain, 2019; ISBN 9789284420858.

25. Santos, M.C.; Ferreira, A.; Costa, C.; Santos, J.A.C. A model for the development of innovative tourism products: From service to transformation. Sustainability 2020, 12, 4362. [CrossRef]

26. Waligo, V.M.; Clarke, J.; Hawkins, R. Implementing sustainable tourism: A multi-stakeholder involvement management framework. Tour. Manag. 2013, 36, 342-353. [CrossRef]

27. Xu, J.B. Perceptions of tourism products. Tour. Manag. 2010, 31, 607-610. [CrossRef]

28. McKercher, B. Towards a taxonomy of tourism products. Tour. Manag. 2016, 54, 196-208. [CrossRef]

29. Harrison, J.S.; Wicks, A.C. Stakeholder Theory, Value, and Firm Performance. Bus. Ethics Q. 2013, 23, 97-124. [CrossRef]

30. Robert Phillips, A.; Freeman, R.E.; Wicks, A. What stakeholder theory is not. Bus. Ethics Q. 2014, 13, 479-502. [CrossRef]

31. Laplume, A.O.; Sonpar, K.; Litz, R.A. Stakeholder theory: Reviewing a theory that moves us. J. Manag. 2008, 34, 1152-1189. [CrossRef]

32. Goyal, L. Stakeholder theory: Revisiting the origins. J. Public Aff. 2020. [CrossRef]

33. Freeman, R.E. Strategic Management: A Stakeholder Approach; Pitman: Boston, MA, USA, 1984

34. Goeldner, C.R.; Ritchie, J.R.B. Tourism: Principles, Practices and Philosophies; John Wiley and Sons: Hoboken, NJ, USA, 2005; ISBN 9780470084595.

35. Boom, S.; Weijschede, J.; Melissen, F.; Koens, K.; Mayer, I. Identifying stakeholder perspectives and worldviews on sustainable urban tourism development using a Q-sort methodology. Curr. Issues Tour. 2020, 0, 1-16. [CrossRef]

36. Byrd, E.T.; Bosley, H.E.; Dronberger, M.G. Comparisons of stakeholder perceptions of tourism impacts in rural eastern North Carolina. Tour. Manag. 2009, 30, 693-703. [CrossRef]

37. Kuvan, Y.; Akan, P. Conflict and agreement in stakeholder attitudes: Residents' and hotel managers' views of tourism impacts and forest-related tourism development. J. Sustain. Tour. 2012, 20, 571-584. [CrossRef]

38. Poudel, S.; Nyaupane, G.P.; Budruk, M. Stakeholders' Perspectives of Sustainable Tourism Development: A New Approach to Measuring Outcomes. J. Travel Res. 2014, 55, 465-480. [CrossRef]

39. González Herrera, M.R.; Sasidharan, V.; Álvarez Hernández, J.A.; Herrera Azpeitia, L.D. Quality and sustainability of tourism development in Copper Canyon, Mexico: Perceptions of community stakeholders and visitors. Tour. Manag. Perspect. 2018, 27, 91-103. [CrossRef]

40. Bramwell, B.; Lane, B. Critical research on the governance of tourism and sustainability. J. Sustain. Tour. 2011, 19, 411-421. [CrossRef]

41. Bramwell, B. Governance, the state and sustainable tourism: A political economy approach. J. Sustain. Tour. 2011, 19, 459-477. [CrossRef]

42. Ruhanen, L. Local government: Facilitator or inhibitor of sustainable tourism development? J. Sustain. Tour. 2013, 21, 80-98. [CrossRef]

43. Sautter, E.T.; Leisen, B. Managing stakeholders: A tourism planning model. Ann. Tour. Res. 1999, 26, 312-328. [CrossRef]

44. James, L.; Olsen, L.S.; Karlsdóttir, A. Sustainability and cruise tourism in the arctic: Stakeholder perspectives from Ísafjörður, Iceland and Qaqortoq, Greenland. J. Sustain. Tour. 2020, 28, 1425-1441. [CrossRef]

45. Vellecco, I.; Mancino, A. Sustainability and tourism development in three Italian destinations: Stakeholders' opinions and behaviours. Serv. Ind. J. 2010, 30, 2201-2223. [CrossRef]

46. Niñerola, A.; Sánchez-Rebull, M.V.; Hernández-Lara, A.B. Tourism research on sustainability: A bibliometric analysis. Sustainability 2019, 11, 1377. [CrossRef]

47. Scholtz, M.; Slabbert, E. A remodelled approach to measuring the social impact of tourism in a developing country. Dev. South Afr. 2018, 35, 743-759. [CrossRef]

48. Chan, C.S.; Nozu, K.; Zhou, Q. Tourism stakeholder perspective for disaster-management process and resilience: The case of the 2018 Hokkaido Eastern Iburi Earthquake in Japan. Sustainability 2020, 12, 7882. [CrossRef]

49. Castellani, V.; Sala, S. Sustainable performance index for tourism policy development. Tour. Manag. 2010, 31, 871-880. [CrossRef]

50. García-Rosell, J.C.; Mäkinen, J. An integrative framework for sustainability evaluation in tourism: Applying the framework to tourism product development in Finnish Lapland. J. Sustain. Tour. 2013, 21, 396-416. [CrossRef] 
51. Schianetz, K.; Kavanagh, L. Sustainability indicators for tourism destinations: A complex adaptive systems approach using systemic indicator systems. J. Sustain. Tour. 2008, 16, 601-628. [CrossRef]

52. Moyle, B.D.; McLennan, C.; Moyle, C.-L.; Ruhanen, L.; Weiler, B. Tracking the concept of sustainability in Australian tourism policy and planning documents. J. Sustain. Tour. 2014, 22, 1037-1051. [CrossRef]

53. Serrano, L.; Sianes, A.; Ariza-Montes, A. Using bibliometric methods to shed light on the concept of sustainable tourism. Sustainability 2019, 11, 6964. [CrossRef]

54. Lozano-Oyola, M.; Blancas, F.J.; González, M.; Caballero, R. Sustainable tourism indicators as planning tools in cultural destinations. Ecol. Indic. 2012, 18, 659-675. [CrossRef]

55. Renfors, S.M. Stakeholders' Perceptions of Sustainable Tourism Development in a Cold-Water Destination: The Case of the Finnish Archipelago. Tour. Plan. Dev. 2020, 10, 1-19. [CrossRef]

56. Ko, J.T.G. Assessing progress of tourism sustainability. Ann. Tour. Res. 2001, 28, 817-820. [CrossRef]

57. Ko, T.G. Development of a tourism sustainability assessment procedure: A conceptual approach. Tour. Manag. 2005, 26, 431-445. [CrossRef]

58. Franzoni, S. Measuring the sustainability performance of the tourism sector. Tour. Manag. Perspect. 2015, 16, 22-27. [CrossRef]

59. World Tourism Organization [UNWTO]. Indicators of Sustainable Development for Tourism Destinations: A Guidebook; World Tourism Organization [UNWTO]: Madrid, Spain, 2004; ISBN 92-844-0726-5.

60. Blancas, F.J.; Lozano-Oyola, M.; González, M.; Guerrero, F.M.; Caballero, R. How to use sustainability indicators for tourism planning: The case of rural tourism in Andalusia (Spain). Sci. Total Environ. 2011, 412, 28-45. [CrossRef] [PubMed]

61. Lozano-Oyola, M.; Contreras, I.; Blancas, F.J. An Operational Non-compensatory Composite Indicator: Measuring Sustainable Tourism in Andalusian Urban Destinations. Ecol. Econ. 2019, 159, 1-10. [CrossRef]

62. Asmelash, A.G.; Kumar, S. Assessing progress of tourism sustainability: Developing and validating sustainability indicators Tour. Manag. 2019, 71, 67-83. [CrossRef]

63. Liu, C.R.; Lin, W.R.; Wang, Y.C.; Chen, S.P. Sustainability indicators for festival tourism: A multi-stakeholder perspective. J. Qual. Assur. Hosp. Tour. 2019, 20, 296-316. [CrossRef]

64. Cucculelli, M.; Goffi, G. Does sustainability enhance tourism destination competitiveness? Evidence from Italian Destinations of Excellence. J. Clean. Prod. 2016, 111, 370-382. [CrossRef]

65. Ruiz-Lozano, M.; Tirado-Valencia, P.; Sianes, A.; Ariza-Montes, A.; Fernández-Rodríguez, V.; López-Martín, M.C. SROI methodology for public administration decisions about financing with social criteria. A case study. Sustainability 2020, $12,1070$. [CrossRef]

66. Olsen, S.; Galimidi, B. Catalog of Approaches to Impact Measurement; The Rockfeller Foundation: New York, NY, USA, 2008.

67. Rosenzweig, W. Double Bottom Line Project Report: Assessing Social Impact in Double Bottom Line Ventures; UC Berkeley: Center for Responsible Business. 2004. Available online: https:/ / escholarship.org/uc/item/80n4f1mf (accessed on 31 July 2020).

68. Maas, K. Corporate Social Performance: From Output Measurement to Impact Measurement; Ph.D. Series 182; Erasmus Research Institute of Management: Rotterdam, The Netherlands, 2009.

69. Tuan, M.T. Mesuring and/or Estimating Social Value Creation: Insights into Eight Integrated Cost; Bill \& Melinda Gates Foundations: Seattle, WA, USA, 2008.

70. Nicholls, J.; Lawlor, E.; Neitzert, E.; Goodspeed, T. A Guide to Social Return on Investment (SROI) (Revised) London, UK, UK Cabinet Office-Office of the Third Sector. 2012. Available online: http://www.socialvalueuk.org/app/uploads/2016/03/The\% 20Guide\%20to\%20Social\%20Return\%20on\%20Investment\%202015.pdf (accessed on 4 March 2020).

71. Rogers, P. Theory of Change: Methodological Briefs_Impact Evaluation No. 2; UNICEF Office of Research: Florence, Italy, 2014.

72. Vogel, I. Review of the Use of "Theory of Change" in International Development. 2012. Available online: http://www. theoryofchange.org/pdf/DFID_ToC_Review_VogelV7.pdf (accessed on 30 September 2020).

73. Lawlor, E.; Neitzert, E.; Nicholls, J. Measuring Value: A Guide to Social Return on Investment (SROI), 2nd ed.; The New Economics Foundation: London, UK, 2008. 